Article

\title{
The Residual Lifetime of Surviving Components of Coherent System under Periodical Inspections
}

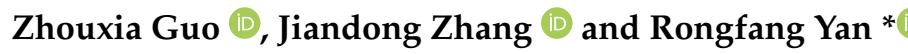 \\ College of Mathematics and Statistics, Northwest Normal University, Lanzhou 730070, China; \\ 2018211710@nwnu.edu.cn (Z.G.); 2019115086@nwnu.edu.cn (J.Z.) \\ * Correspondence: yanrf@nwnu.edu.cn
}

Received: 15 September 2020; Accepted: 4 December 2020; Published: 7 December 2020

check for updates

\begin{abstract}
In this manuscript, we gain a mixture representation for reliability function of the residual lifetime of unfailed components in a coherent system under periodical inspections, given that the number of failed components before time $t_{1}$ is $r(\geq 0)$, but the system is still operating at time $t_{1}$, and the system eventually failed at time $t_{2}\left(>t_{1}\right)$. Some aging properties and stochastic orders of the residual lifetime on survival components are also established. Finally, some numerical examples and graphs are given in order to confirm the theoretical results.
\end{abstract}

Keywords: residual lifetime; coherent system; periodical inspection; signature vector; stochastic orders

MSC: 90B25; 60E15; 60K10

\section{Introduction}

Reliability is one of the most crucial properties of coherent systems; it is widely used in many engineering fields and is significant to scholars and engineers. A system that consists of $n(n \geq 1)$ components is called a coherent system, such that the structure function of the system is monotone at each component and there are no irrelevant components in the system (i.e., irrelevant components mean that their performance will not affect the performance of the system), see [1] to know more details regarding the coherent systems.

Suppose that a coherent system has $n$ components with independent and identically distributed (i.i.d.) lifetimes $X_{1}, X_{2}, \ldots, X_{n}$, where $X_{i}$ has an absolutely continuous distribution function (CDF) $F$. Let $X_{1: n}, X_{2: n}, \ldots, X_{n: n}$ be the ordered statistics of components lifetimes and $\tau$ is structure function of coherent system, then $T=\tau\left(X_{1}, X_{2}, \ldots, X_{n}\right)$ can express the lifetime of coherent system. For example, a series system has lifetime $\tau\left(X_{1}, X_{2}, \ldots, X_{n}\right)=\min \left(X_{1}, X_{2}, \ldots, X_{n}\right)$ and a parallel system has lifetime $\tau\left(X_{1}, X_{2}, \ldots, X_{n}\right)=\max \left(X_{1}, X_{2}, \ldots, X_{n}\right)$. If $\bar{F}_{T}$ denotes the reliability function of coherent systems lifetime $T$, then $\bar{F}_{T}$ is denoted by

$$
\bar{F}_{T}(t)=\sum_{i=1}^{n} s_{i} \bar{F}_{i: n}(t)
$$

where $s_{i}=P\left(T=X_{i: n}\right)$ is the element of probability vector $\mathbf{s}, \bar{F}_{i: n}(t)$ is survival function of $X_{i: n}, i=1,2, \ldots, n$. We call the probability vector $\mathbf{s}=\left(s_{1}, s_{2}, \ldots, s_{n}\right)$ as the signature vector of the coherent system, and it is a vital tool for studying the lifetime of coherent systems, see [2,3] for more details regarding the signature vector of coherent system. Ref. [4] demonstrated that the representation (3) is still valid when the components of coherent system are exchangeable. Ref. [5] developed the concept of signature of coherent systems with dependent components. Equation (1) is 
a great tool for scholars and engineers to research the reliability properties of coherent systems. The residual lifetime and past lifetime of coherent system are some significantly concepts in reliability theory and survival analysis. In the past decades, a lot of scholars have shown extreme interest in investigating the lifetimes of a coherent system or the components of a coherent system. There have been many articles regarding the residual lifetime and past lifetime of coherent systems in the literature; one can refer to [6-15]. However, there are few results in the literature about the residual lifetime and past lifetime of components in a coherent system. To the best of our knowledge, only few results in the literature, for example, ref. [16-20].

Consider a coherent system with $n$ i.i.d. components, and suppose that the signature vector of the system, as following:

$$
\mathbf{s}=\left(s_{1}, s_{2}, \ldots, s_{i}, 0, \ldots, 0\right), i=1, \ldots, n-1 .
$$

It is obvious that a coherent system has a signature vector of form (2), which has the property when the system failed, the components with lifetime $X_{k: n}(k=i+1, \ldots, n)$ remains alive in a coherent system; meanwhile, these unfailed components can be removed from the original system and used for other points, such as placing on another system (cf. [18,19]). Therefore, the investigation of the stochastic and aging properties of these unfailed components in system may be of interest for engineers.

Under a coherent system with signature vector of form (2), ref. [18] considered the reliability of the residual lifetime of unfailed components under the assuption that the system has failed before time $t$, but the component with lifetime $X_{k: n}, k=i+1, \ldots, n$ is still alive at time $t$; they researched the stochastic orders and aging properties of the residual lifetime of unfailed components by random variables, as follows:

$$
\left(X_{k: n}-t \mid T<t<X_{k: n}\right), k=i+1, \ldots, n .
$$

Ref. [19] investigated the reliability properties of the residual lifetimes on unfailed components in a coherent system on the conditional that the failure time of the system is time $t$. They explored the following conditional random variables in order to consider the residual lifetime of unfailed components in coherent system:

$$
\left(X_{k: n}-t \mid T=t\right), k=i+1, \ldots, n .
$$

In real-life case, a system is planned to be monitored at different times. Under these periodical monitors, engineers would obtain some information regarding the system. It is impossible or expensive in practical life because of continuous inspection; thus, a coherent system is planned to be monitored twice at different times. In more recent years, some scholars have considered the residual lifetime of coherent systems under double monitoring, one can see [21-27].

Our main work extends two conditional random variables of (3) and (4) to the case of double monitoring (5), and considers the statistical properties of the residual lifetime on unfailed components in a coherent system, such as the stochastic orders and aging properties. As shown in Figure 1, assume that the system is monitored once at time $t_{1}$, and it is observed that there are $r$ components $(0 \leq r<i)$ have failed and the system is still functioning. Subsequently, the system failed at time $t_{2}\left(>t_{1}\right)$. This manuscript mainly considers a coherent system with $n$ i.i.d. components where the signature vector of the system has the form (2), and we are interested in investigating the residual lifetime of unfailed components in coherent system

$$
R X_{k: n}\left(t_{1}, t_{2}\right)=\left(X_{k: n}-t_{2} \mid X_{r: n}<t_{1}<X_{r+1: n}, T=t_{2}\right), \text { for } 0 \leq r<k \leq n .
$$

In fact, $R X_{k: n}\left(t_{1}, t_{2}\right)$ is the residual lifetime of unfailed components $X_{k: n}(k=i+1, \ldots, n)$ in the coherent system at time $t_{2}\left(>t_{1}\right)$. 


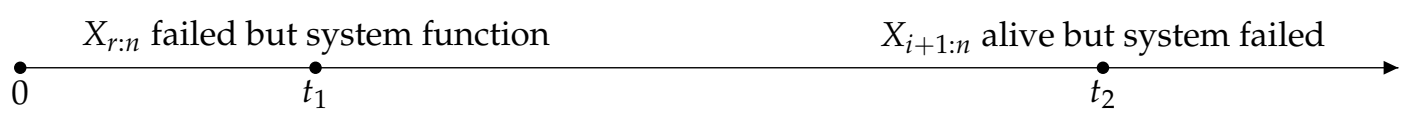

Figure 1. The number of failed comments is exactly $r(<i<n)$ at time $t_{1}(>0)$, and the system failed at time $t_{2}\left(>t_{1}\right)$.

The remainder of this manuscript fanning, as follows. In Section 2, we provide some definitions of the stochastic orders and useful lemmas. In Section 3, we will derive a mixture representation for the survival function of the residual lifetime on unfailed components, obtain several stochastic comparisons between two coherent systems, and some aging properties that are based on the proposed conditional random variable. Finally, some conclusions and remarks are made in Section 4.

\section{Preliminaries}

The term increasing and decreasing are used instead of monotone non-decreasing and monotone non-increasing, respectively. For the sake of discussion, we denote $\mathbb{R}^{+}=(0,+\infty)$. Before introducing the results of this manuscript, we will recall some basic definitions on the stochastic orders, and it will be discussed in our subsequent discussion.

Definition 1. Suppose that $X$ and $Y$ are two random variables with distribution functions $F(x)$ and $G(x)$, survival functions $\bar{F}(x)=1-F(x)$ and $\bar{G}(x)=1-G(x)$, and density functions $f(x)$ and $g(x)$, respectively. If $X$ is said to be smaller than $Y$ in the stochastic orders, then:

(i) the usual stochastic order (denoted by $X \leq_{s t} Y$ ) if $\bar{F}(x) \leq \bar{G}(x)$ for all $x \in \mathbb{R}^{+}$;

(ii) the hazard rate order (denoted by $X \leq_{h r} Y$ ) if $\bar{G}(x) / \bar{F}(x)$ is increasing in $x \in \mathbb{R}^{+}$;

(iii) the reversed hazard rate order (denoted by $X \leq_{r h} Y$ ) if $G(x) / F(x)$ is increasing in $x \in \mathbb{R}^{+}$;

(iv) the likelihood ratio order (denoted by $X \leq_{l r} Y$ ) if $g(x) / f(x)$ is increasing in $x \in \mathbb{R}^{+}$.

Let $\mathbf{p}=\left(p_{1}, p_{2}, \ldots, p_{n}\right)$ and $\mathbf{q}=\left(q_{1}, q_{2}, \ldots, q_{n}\right)$ be two discrete probability distributions, if $\mathbf{p}$ is said to be smaller than $\mathbf{q}$ in the stochastic orders, then

(i) $\mathbf{p} \leq_{s t} \mathbf{q}$, if $\sum_{i=j}^{n} p_{i} \leq \sum_{i=j}^{n} q_{i}, j=1,2, \ldots, n$;

(ii) $\mathbf{p} \leq_{l r} \mathbf{q}$, if $q_{j} / p_{j}$ is increasing in $j$.

As is well known, the likelihood ratio order means that the (reversed) hazard rate order and the usual stochastic order; the (reversed) hazard rate order also implies the usual stochastic order, but the reversed statement is not true in general. One can refer to $[28,29]$ in order to know more properties and details about the various stochastic orders.

The following lemma plays a crucial role in founding the main results.

Lemma 1 ([28]). (i) Let $X_{1}, X_{2}, \ldots, X_{n}$ be $n$ independent random variables, all with absolutely continuous distribution functions, all having the same supportm which is an interval of the real line, and all having differentiable densities. If $X_{1} \leq_{l r} X_{2} \leq_{l r} \cdots \leq_{l r} X_{n}$, then $X_{k-1: n} \leq_{l r} X_{k: n}, 2 \leq k \leq n$, and $X_{k-1: n-1} \leq_{l r} X_{k: n}, 2 \leq k \leq n$.

(ii) If $X \leq_{s t} Y$ and $g$ is any increasing [decreasing] function, then $g(X) \leq_{s t}\left[\geq_{s t}\right] g(Y)$.

(iii) Let $\alpha$ and $\beta$ be the real valued function such that $\beta$ is nonnegative, and $\alpha / \beta$ and $\beta$ are decreasing. If $X_{1} \leq_{r h} X_{2,}$, then

$$
E\left[\alpha\left(X_{1}\right)\right] E\left[\beta\left(X_{2}\right)\right] \geq E\left[\alpha\left(X_{2}\right)\right] E\left[\beta\left(X_{1}\right)\right] .
$$

(iii) Let $\alpha$ and $\beta$ be the real valued function, such that $\beta$ is nonnegative, and $\alpha / \beta$ and $\beta$ are increasing. If $X_{1} \leq_{h r} X_{2}$, then

$$
E\left[\alpha\left(X_{1}\right)\right] E\left[\beta\left(X_{2}\right)\right] \leq E\left[\alpha\left(X_{2}\right)\right] E\left[\beta\left(X_{1}\right)\right] .
$$

\section{Main Result}

Let $T$ be the lifetime of a coherent system that has $n$ i.i.d. components with lifetimes $X_{1}, X_{2}, \ldots, X_{n}$, and $X_{i}$ has distribution function $F$. When considering the coherent system with the signature vector 
of form (2) under the assumption that the number of failed components is $r(0 \leq r<i)$ at time $t_{1}$, the system is still functioning at time $t_{1}$, and the system failed at time $t_{2}\left(>t_{1}\right)$.

The following theorem provides the representation of the reliability function for the residual lifetimes $R X_{k: n}\left(t_{1}, t_{2}\right)$ of unfailed components with lifetime $X_{k: n}, k=i+1, \ldots, n$ in a coherent system. Following Equation (6), the reliability function of $R X_{k: n}\left(t_{1}, t_{2}\right)$ can be expressed as a mixture representation of the residual lifetime on the unfailed components with lifetime $X_{k: n}, k=i+1, \ldots, n$ in a $(n-m+1)$-out-of- $n$ system on the condition that exactly $r(r<i)$ components have failed before time $t_{1}\left(t_{1} \geq 0\right)$, and the system has failed at time $t_{2}$ (cf. $\left.[18,19,30]\right)$. Hence, by this mixture representation of the reliability function on the residual lifetime $R X_{k: n}\left(t_{1}, t_{2}\right)$, we can further investigate the statistical properties of the residual lifetime on unfailed components in a coherent system under the scenario of double monitoring, such as the stochastic orders and aging properties.

Theorem 1. Assume that $X_{1: n}, X_{2: n}, \ldots, X_{n: n}$ are the order statistics of the random variables $X_{1}, X_{2}, \ldots, X_{n}$. Subsequently, for any $0 \leq r<k, i=2, \ldots, n$ and $0<t_{1}<t_{2}$, the reliability function of $R X_{k: n}\left(t_{1}, t_{2}\right)$ can be represented as

$$
\begin{aligned}
\mathbb{P}\left(R X_{k: n}\left(t_{1}, t_{2}\right)>x\right) & =\mathbb{P}\left(X_{k: n}-t_{2}>x \mid X_{r: n}<t_{1}<X_{r+1: n}, T=t_{2}\right) \\
& =\sum_{m=r+1}^{i} q_{m}\left(r, t_{1}, t_{2}\right) P\left(X_{k: n}-t_{2}>x \mid A r\left(t_{1}\right), X_{m: n}=t_{2}\right)
\end{aligned}
$$

where $\operatorname{Ar}\left(t_{1}\right)$ denotes the event $\left\{X_{r: n}<t_{1}<X_{r+1: n}\right\}$, and

$$
q_{m}\left(r, t_{1}, t_{2}\right)=\mathbb{P}\left(T=X_{m: n} \mid A r\left(t_{1}\right), T=t_{2}\right) .
$$

Proof. For any $x \in \mathbb{R}^{+}$and $0<t_{1}<t_{2}$, the reliability function of $R X_{k: n}\left(t_{1}, t_{2}\right)$ can be represented as

$$
\begin{aligned}
& \mathbb{P}\left(R X_{k: n}\left(t_{1}, t_{2}\right)>x\right) \\
= & P\left(X_{k: n}-t_{2}>x \mid X_{r: n}<t_{1}<X_{r+1: n}, T=t_{2}\right) \\
= & \sum_{m=1}^{i} P\left(X_{k: n}-t_{2}>x, T=X_{m: n} \mid \operatorname{Ar}\left(t_{1}\right), T=t_{2}\right) \\
= & \sum_{m=r+1}^{i} P\left(X_{k: n}-t_{2}>x \mid \operatorname{Ar}\left(t_{1}\right), T=t_{2}, T=X_{m: n}\right) \mathbb{P}\left(T=X_{m: n} \mid \operatorname{Ar}\left(t_{1}\right), T=t_{2}\right) \\
= & \sum_{m=r+1}^{i} q_{m}\left(r, t_{1}, t_{2}\right) P\left(X_{k: n}-t_{2}>x \mid \operatorname{Ar}\left(t_{1}\right), X_{m: n}=t_{2}\right) .
\end{aligned}
$$

Let $h_{i}>0(i=1,2)$, we have

$$
\begin{aligned}
q_{m}\left(r, t_{1}, t_{2}\right) & =\mathbb{P}\left(T=X_{m: n} \mid A r\left(t_{1}\right), T=t_{2}\right) \\
& =\frac{\mathbb{P}\left(T=X_{m: n}, A r\left(t_{1}\right), T=t_{2}\right)}{\mathbb{P}\left(A r\left(t_{1}\right), T=t_{2}\right)} \\
& =\frac{\mathbb{P}\left(A r\left(t_{1}\right), T=t_{2} \mid T=X_{m: n}\right) \mathbb{P}\left(T=X_{m: n}\right)}{\sum_{j=r+1}^{i} \mathbb{P}\left(A r\left(t_{1}\right), T=t_{2}, T=X_{j: n}\right)} \\
& =\frac{\mathbb{P}\left(A r\left(t_{1}\right), T=t_{2} \mid T=X_{m: n}\right) \mathbb{P}\left(T=X_{m: n}\right)}{\sum_{j=r+1}^{i} \mathbb{P}\left(A r\left(t_{1}\right), T=t_{2} \mid T=X_{j: n}\right) \mathbb{P}\left(T=X_{j: n}\right)} \\
& =\frac{s_{m} \lim _{h_{1} \rightarrow 0} \mathbb{P}\left(A r\left(t_{1}\right), t_{2} \leq X_{m: n} \leq t_{2}+h_{1}\right)}{\sum_{j=r+1}^{i} s_{j} \lim _{h_{2} \rightarrow 0} \mathbb{P}\left(A r\left(t_{1}\right), t_{2} \leq X_{j: n} \leq t_{2}+h_{2}\right)} \\
& =\frac{s_{m} \frac{n !}{r !(m-r-1) !(n-m) !} F^{r}\left(t_{1}\right)\left(F\left(t_{2}\right)-F\left(t_{1}\right)\right)^{m-r-1} \bar{F}^{n-m}\left(t_{2}\right)}{\sum_{j=r+1}^{i} s_{j !} \frac{n !}{r ! j-r-1) !(n-j) !} F^{r}\left(t_{1}\right)\left(F\left(t_{2}\right)-F\left(t_{1}\right)\right)^{j-r-1} \bar{F}^{n-j}\left(t_{2}\right)}
\end{aligned}
$$




$$
\begin{aligned}
& =\frac{s_{m} C_{r, m}^{n}\left(F\left(t_{2}\right)-F\left(t_{1}\right)\right)^{m-r-1} \bar{F}^{n-m}\left(t_{2}\right)}{\sum_{j=r+1}^{i} s_{j} C_{r, j}^{n}\left(F\left(t_{2}\right)-F\left(t_{1}\right)\right)^{j-r-1} \bar{F}^{n-j}\left(t_{2}\right)} \\
& =\frac{s_{m} C_{r, m}^{n}\left(\frac{\bar{F}\left(t_{1}\right)-\bar{F}\left(t_{2}\right)}{\bar{F}\left(t_{2}\right)}\right)^{m}}{\sum_{j=r+1}^{i} s_{j} C_{r, j}^{n}\left(\frac{\bar{F}\left(t_{1}\right)-\bar{F}\left(t_{2}\right)}{\bar{F}\left(t_{2}\right)}\right)^{j}} \\
& =\frac{s_{m} C_{r, m}^{n}\left(\phi\left(t_{1}, t_{2}\right)\right)^{m}}{\sum_{j=r+1}^{i} s_{j} C_{r, j}^{n}\left(\phi\left(t_{1}, t_{2}\right)\right)^{j}},
\end{aligned}
$$

where $\phi\left(t_{1}, t_{2}\right)=\frac{\bar{F}\left(t_{1}\right)-\bar{F}\left(t_{2}\right)}{\bar{F}\left(t_{2}\right)}, C_{r, m}^{n}=\frac{n !}{r !(m-r-1) !(n-m) !}$.

Remark 1. It is noticed that the probability vector

$$
\mathbf{q}\left(t_{1}, t_{2}\right)=\left(0, \ldots, 0, p_{r+1}\left(r, t_{1}, t_{2}\right), \ldots, p_{i}\left(r, t_{1}, t_{2}\right), 0, \ldots, 0\right)
$$

can be considered to be the conditional signature vector of the coherent system, and it only depends on the distribution function $F$. It follows from Equation (6) that the conditional residual lifetime $R X_{k: n}\left(t_{1}, t_{2}\right)$ of unfailed components under double monitoring can be expressed as the mixture of the residual lifetime $\left(X_{k: n}-\right.$ $\left.t_{2} \mid A r\left(t_{1}\right), X_{m: n}=t_{2}\right)$ of the unfailed components with $X_{k: n}(k>i)$ in a $(n-m+1)$-out-of-n system, under the assumption that the number of failed components is $r(r<i)$ at time $t_{1}\left(t_{1} \geq 0\right)$, and the system failed at time $t_{2}$. Theorem 1 extends the residual lifetime of the unfailed components in [19] to the scenario of double monitoring.

Next, consider the reliability function of $\left(X_{k: n}-t_{2} \mid A r\left(t_{1}\right), X_{m: n}=t_{2}\right)$. It is noted that $\left(X_{k: n}-\right.$ $\left.t_{2} \mid A r\left(t_{1}\right), X_{m: n}=t_{2}\right)$ and $Z_{k-m: n-m}^{t_{2}}$ have the same distribution function. We have the following lemma.

Lemma 2. For $m=r+1, \ldots, i$, and $0 \leq r<k$, we have

$$
\left(X_{k: n}-t_{2} \mid A r\left(t_{1}\right), X_{m: n}=t_{2}\right) \stackrel{\mathrm{d}}{=} Z_{k-m: n-m^{\prime}}^{t_{2}}
$$

where $\stackrel{\mathrm{d}}{=}$ denotes equality in distribution, and $\mathrm{Z}_{k-m: n-m}^{t_{2}}$ is the $(k-m)$ th order statistics in $(n-m)$ i.i.d. random variables with survival function

$$
\bar{G}_{t_{2}}(x)=\frac{\bar{F}\left(t_{2}+x\right)}{\bar{F}\left(t_{2}\right)}, \quad x \in \mathbb{R}^{+} .
$$

Proof. Let $h$ be a small positive real number, the reliability function of $\left(X_{k: n}-t_{2} \mid A r\left(t_{1}\right), X_{m: n}=t_{2}\right)$ is given as

$$
\begin{aligned}
& \mathbb{P}\left(X_{k: n}-t_{2} \mid \operatorname{Ar}\left(t_{1}\right), X_{m: n}=t_{2}\right) \\
= & \lim _{h \rightarrow 0} \frac{\mathbb{P}\left(X_{k: n}-t_{2}>x, A r\left(t_{1}\right), t_{2} \leq X_{m: n} \leq t_{2}+h\right)}{\mathbb{P}\left(A r\left(t_{1}\right), t_{2} \leq X_{m: n} \leq t_{2}+h\right)} \\
= & \sum_{j=n-k+1}^{n-m}\left(\begin{array}{c}
n-m \\
j
\end{array}\right) \frac{\left(F\left(t_{2}+x\right)-F\left(t_{2}\right)\right)^{n-m-j} \bar{F}^{j}\left(t_{2}+x\right)}{\bar{F}^{n-m}\left(t_{2}\right)} \\
= & \sum_{j=n-k+1}^{n-m}\left(\begin{array}{c}
n-m \\
j
\end{array}\right)\left(\bar{G}_{t_{2}}(x)\right)^{j}\left(1-\bar{G}_{t_{2}}(x)\right)^{n-m-j},
\end{aligned}
$$

where $\bar{G}_{t_{2}}(x)=\frac{\bar{F}\left(t_{2}+x\right)}{\bar{F}\left(t_{2}\right)}$. Thus, from (7), we obtain the equality in distribution

$$
\left(X_{k: n}-t_{2} \mid A r\left(t_{1}\right), X_{m: n}=t_{2}\right) \stackrel{\mathrm{d}}{=} Z_{k-m: n-m}^{t_{2}}
$$


The proof of the result is completed.

Example 1. Assume that $X_{1}, X_{2}, X_{3}$, and $X_{4}$ are i.i.d. random variables. Let $T=\min \left(X_{1}, X_{2}, X_{3}\right)$ be the lifetime of a coherent system, where the signature vector of the system is $\mathbf{s}=\left(\frac{3}{4}, \frac{1}{4}, 0,0\right)$. Suppose that there is one component failed before time $t_{1}$, but the system failed at time $t_{2}\left(>t_{1}\right)$. The residual lifetime of unfailed components $X_{k: n}, k=i+1, \ldots, n$ is given by

$$
R X_{k: n}\left(t_{1}, t_{2}\right)=\left(X_{k: n}-t_{2} \mid \operatorname{Ar}\left(t_{1}\right), T=t_{2}\right) .
$$

Now, according to Theorem 1 , the survival function of $R X_{k: n}\left(t_{1}, t_{2}\right)$ can be written as

$$
\begin{aligned}
\mathbb{P}\left(R X_{k: n}\left(t_{1}, t_{2}\right)>x\right) & =\mathbb{P}\left(X_{k: n}-t_{2}>x \mid \operatorname{Ar}\left(t_{1}\right), T=t_{2}\right) \\
& =\sum_{m=r+1}^{i} q_{m}\left(r, t_{1}, t_{2}\right) \mathbb{P}\left(X_{k: n}-t_{2}>x \mid \operatorname{Ar}\left(t_{1}\right), X_{m: n}=t_{2}\right) .
\end{aligned}
$$

For $r=1, k=3$, we have

$$
\mathbb{P}\left(X_{3: 4}-t_{2}>x \mid A r\left(t_{1}\right), T=t_{2}\right)=q_{2}\left(1, t_{1}, t_{2}\right) \mathbb{P}\left(X_{3: 4}-t_{2}>x \mid A r\left(t_{1}\right), X_{2: 4}=t_{2}\right),
$$

where

$$
q_{2}\left(1, t_{1}, t_{2}\right)=1, \quad P\left(X_{3: 4}-t_{2}>x \mid A r\left(t_{1}\right), X_{2: 4}=t_{2}\right)=\left(\frac{\bar{F}\left(t_{2}+x\right)}{\bar{F}\left(t_{2}\right)}\right)^{2}, \quad x \in \mathbb{R}^{+} .
$$

Thus,

$$
\mathbb{P}\left(R X_{3: 4}\left(t_{1}, t_{2}\right)>x\right)=\mathbb{P}\left(X_{3: 4}-t_{2}>x \mid A r\left(t_{1}\right), T=t_{2}\right)=\left(\frac{\bar{F}\left(t_{2}+x\right)}{\bar{F}\left(t_{2}\right)}\right)^{2}, \quad x \in \mathbb{R}^{+} .
$$

For $r=1, k=4$, we have

$$
\mathbb{P}\left(X_{4: 4}-t_{2}>x \mid \operatorname{Ar}\left(t_{1}\right), T=t_{2}\right)=q_{2}\left(1, t_{1}, t_{2}\right) \mathbb{P}\left(X_{4: 4}-t_{2}>x \mid \operatorname{Ar}\left(t_{1}\right), X_{2: 4}=t_{2}\right),
$$

where

$$
q_{2}\left(1, t_{1}, t_{2}\right)=1
$$

and

$$
P\left(X_{4: 4}-t_{2}>x \mid A r\left(t_{1}\right), X_{2: 4}=t_{2}\right)=1-\left(\frac{\bar{F}\left(t_{2}\right)-\bar{F}\left(t_{2}+x\right)}{\bar{F}\left(t_{2}\right)}\right)^{2}, \quad x \in \mathbb{R}^{+} .
$$

Thus,

$$
\mathbb{P}\left(R X_{4: 4}\left(t_{1}, t_{2}\right)>x\right)=\mathbb{P}\left(X_{4: 4}-t_{2}>x \mid A r\left(t_{1}\right), T=t_{2}\right)=1-\left(\frac{\bar{F}\left(t_{2}\right)-\bar{F}\left(t_{2}+x\right)}{\bar{F}\left(t_{2}\right)}\right)^{2}, \quad x \in \mathbb{R}^{+} .
$$
we have

Suppose that $X_{i}$ follows the Weibull distribution (cf. [31]), i.e., $\bar{F}(x)=e^{-\lambda^{\alpha} x^{\alpha}}, x \in \mathbb{R}^{+}$. Subsequently,

$$
\begin{gathered}
\mathbb{P}\left(R X_{3: 4}\left(t_{1}, t_{2}\right)>x\right)=\left(\frac{\bar{F}\left(t_{2}+x\right)}{\bar{F}\left(t_{2}\right)}\right)^{2}=e^{2 \lambda^{\alpha}\left(t_{2}^{\alpha}-\left(t_{2}+x\right)^{\alpha}\right)}, \quad x \in \mathbb{R}^{+}, \\
\mathbb{P}\left(R X_{4: 4}\left(t_{1}, t_{2}\right)>x\right)=1-\left(\frac{\bar{F}\left(t_{2}\right)-\bar{F}\left(t_{2}+x\right)}{\bar{F}\left(t_{2}\right)}\right)^{2}=2 e^{\lambda^{\alpha}\left(t_{2}^{\alpha}-\left(t_{2}+x\right)^{\alpha}\right)}-e^{2 \lambda^{\alpha}\left(t_{2}^{\alpha}-\left(t_{2}+x\right)^{\alpha}\right)}, \quad x \in \mathbb{R}^{+} .
\end{gathered}
$$

Figures 2 and 3 show the graphs of the reliability function of $R X_{3: 4}\left(t_{1}, t_{2}\right)$ and $R X_{4: 4}\left(t_{1}, t_{2}\right)$ in Example 1 when $\alpha=0.6, \lambda=1.1$, and $\alpha=1.3, \lambda=0.8$. 


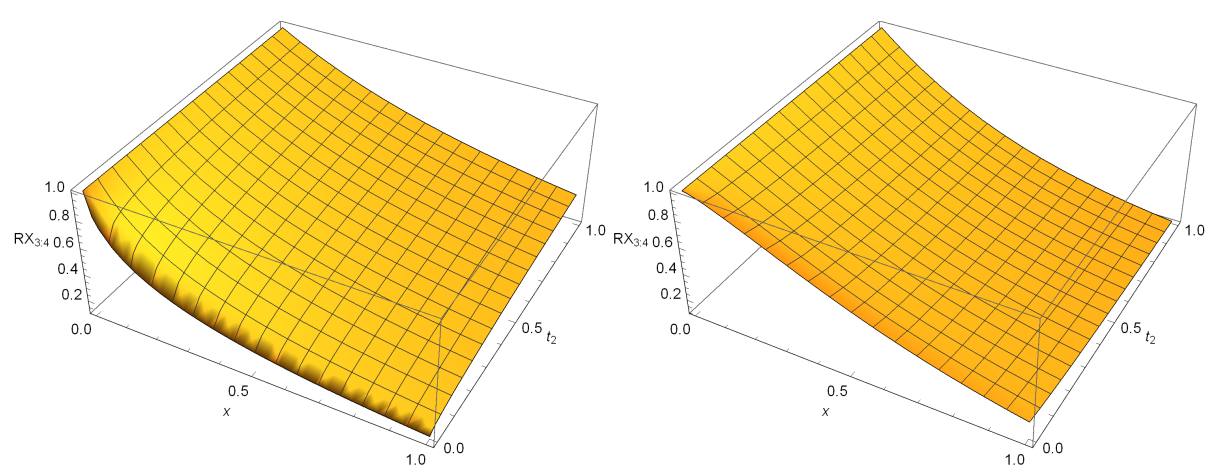

Figure 2. The graphs of the reliability function of $R X_{3: 4}\left(t_{1}, t_{2}\right)$, for the Weibull $(\alpha=0.6, \lambda=1.1)$ (left) and $(\alpha=1.3, \lambda=0.8)$ (right).

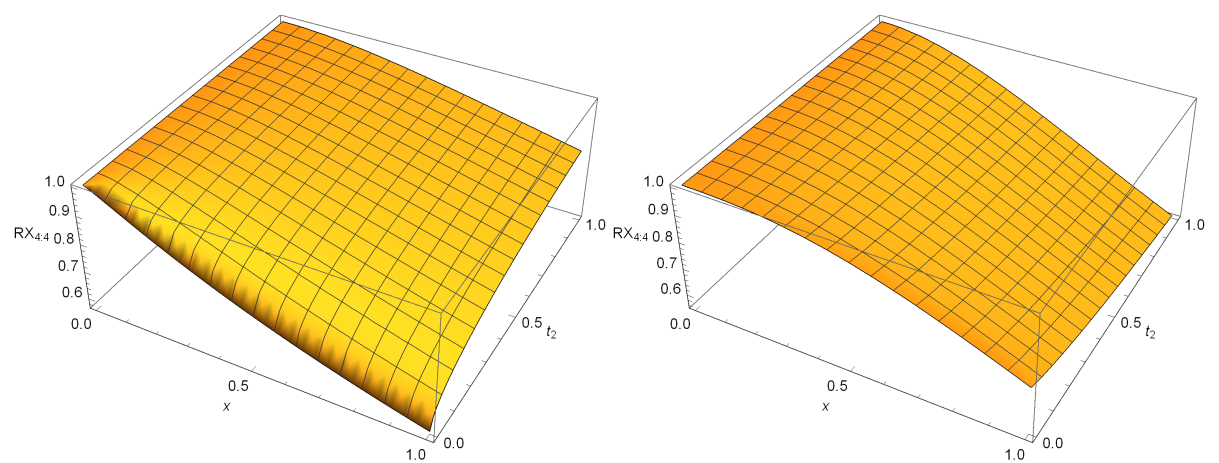

Figure 3. The graphs of the reliability function of $R X_{4: 4}\left(t_{1}, t_{2}\right)$, for the Weibull $(\alpha=0.6, \lambda=1.1)$ (left) and $(\alpha=1.3, \lambda=0.8)$ (right).

The following Theorem 2 compares the conditional residual lifetimes $\left(X_{k: n}-t_{2} \mid A r\left(t_{1}\right), X_{m: n}=t_{2}\right)$ of the unfailed components in two $(n-m+1)$-out-of- $n$ systems by the likelihood ratio order.

Theorem 2. For $l<m$, we have

$$
\left(X_{k: n}-t_{2} \mid A r\left(t_{1}\right), X_{m: n}=t_{2}\right) \leq_{l r}\left(X_{k: n}-t_{2} \mid A r\left(t_{1}\right), X_{l: n}=t_{2}\right)
$$

Proof. Combining Lemma 1(i) with Lemma 2, it holds that

$$
Z_{k-m: n-m}^{t_{2}} \leq l r Z_{k-l: n-l}^{t_{2}}
$$

Remark 2. Theorem 2 shows a $\left(X_{k: n}-t_{2} \mid A r\left(t_{1}\right), X_{m: n}=t_{2}\right)$ decrease in $m$ from the view of the likelihood ratio.

The following theorem provides a sufficient condition of the usual stochastic order for conditional signature vector $\mathbf{q}\left(t_{1}, t_{2}\right)$.

Theorem 3. Suppose that $\mathbf{q}\left(t_{1}, t_{2}\right)$ is the vector of conditional signature $q_{m}\left(r, t_{1}, t_{2}\right)$. If $t_{1} \leq t_{2} \leq t_{3}$, then $\mathbf{q}\left(t_{1}, t_{2}\right) \leq_{s t} \mathbf{q}\left(t_{1}, t_{3}\right)$.

Proof. For obtaining the required conclusion, we need to prove that for all $m \geq r+1$,

$$
\frac{\sum_{j=m}^{n} s_{j} C_{r, j}^{n}\left(\phi\left(t_{1}, t_{2}\right)\right)^{j}}{\sum_{l=r+1}^{n} s_{l} C_{r, l}^{n}\left(\phi\left(t_{1}, t_{2}\right)\right)^{l}} \leq \frac{\sum_{j=m}^{n} s_{j} C_{r, j}^{n}\left(\phi\left(t_{1}, t_{3}\right)\right)^{j}}{\sum_{l=r+1}^{n} s_{l} C_{r, l}^{n}\left(\phi\left(t_{1}, t_{3}\right)\right)^{l}}
$$


which is equivalent to

$$
\begin{aligned}
& \sum_{j=m}^{n} \sum_{l=r+1}^{n} s_{j} s_{l} C_{r, j}^{n} C_{r, l}^{n}\left[\left(\phi\left(t_{1}, t_{3}\right)\right)^{j}\left(\left(\phi\left(t_{1}, t_{2}\right)\right)^{l}-\left(\phi\left(t_{1}, t_{2}\right)\right)^{j}\left(\phi\left(t_{1}, t_{3}\right)\right)^{l}\right]\right. \\
= & \sum_{j=m}^{n} \sum_{l=r+1}^{m-1} s_{j} s_{l} C_{r, j}^{n} C_{r, l}^{n}\left(\phi\left(t_{1}, t_{3}\right)\right)^{l}\left(\phi\left(t_{1}, t_{2}\right)\right)^{l}\left[\left(\phi\left(t_{1}, t_{3}\right)\right)^{j-l}-\left(\phi\left(t_{1}, t_{2}\right)\right)^{j-l}\right] \\
& +\sum_{j=m}^{n} \sum_{l=m}^{n} s_{j} s_{l} C_{r, j}^{n} C_{r, l}^{n}\left[\left(\phi\left(t_{1}, t_{3}\right)\right)^{j}\left(\left(\phi\left(t_{1}, t_{2}\right)\right)^{l}-\left(\phi\left(t_{1}, t_{2}\right)\right)^{j}\left(\phi\left(t_{1}, t_{3}\right)\right)^{l}\right] \geq 0 .\right.
\end{aligned}
$$

It is easily seen that the second term of (8) equals zero, and for $t_{1}<t_{2}<t_{3}$ and $l<j_{\text {, }}$ due to $\phi\left(t_{1}, t_{2}\right)$ increasing in $t_{2}$, thus (8) is nonnegativity. The proof of the result is completed.

Example 2. Assume that $X_{1}, X_{2}, X_{3}$, and $X_{4}$ are i.i.d. random variables. Consider a coherent system with lifetime $T=\min \left(X_{1}, \max \left(X_{2}, X_{3}, X_{4}\right)\right)$, the signature vector of the system is $\mathbf{s}=\left(\frac{1}{4}, \frac{1}{4}, \frac{1}{2}, 0\right)$. Suppose that there is one component failed at time $t_{1}$, and the system failed at time $t_{2}\left(>t_{1}\right)$. It is easy to compute the conditional signature vector of the system that can be written as

$$
q\left(t_{1}, t_{2}\right)=\left(0, \frac{\bar{F}\left(t_{2}\right)}{4 \bar{F}\left(t_{1}\right)-3 \bar{F}\left(t_{2}\right)}, \frac{4 \bar{F}\left(t_{1}\right)-4 \bar{F}\left(t_{2}\right)}{4 \bar{F}\left(t_{1}\right)-3 \bar{F}\left(t_{2}\right)}, 0\right) .
$$

Suppose that $X$ has a Weibull distribution, i.e., $\bar{F}(\lambda, \alpha ; x)=e^{-\lambda^{\alpha} x^{\alpha}}$, let $\lambda=1.7, \alpha=0.6$ and $m=3$. It is follows from Figure 4 that verifies the nonnegativeness of (8); hence, the validity of Theorem 3 is confirmed.
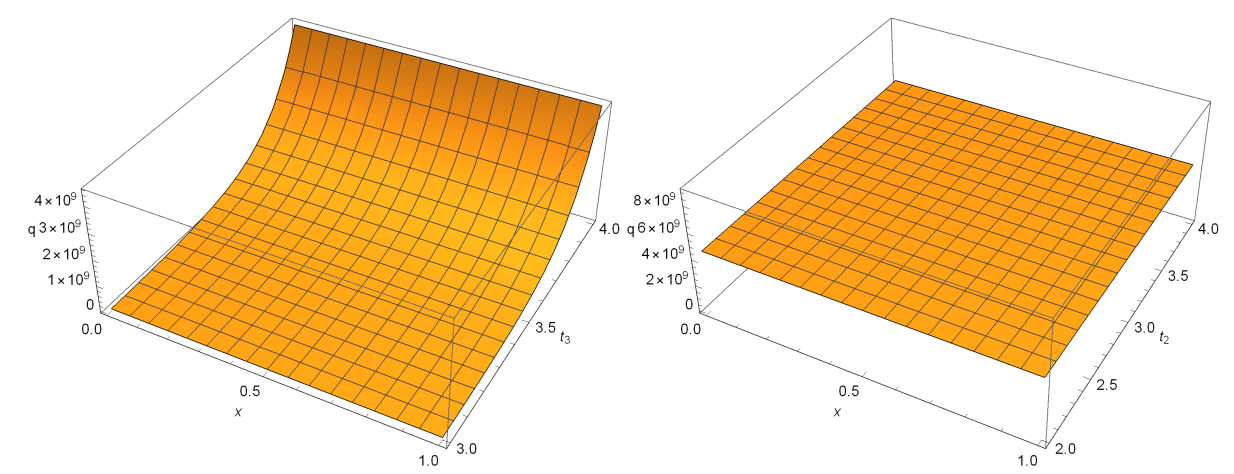

Figure 4. The graphs of the function of $H\left(t_{1}, t_{2}, t_{3}\right)$, for the $t_{1}=1, t_{2}=3$ (left) and $t_{1}=1, t_{3}=4$ (right).

Some sufficient conditions for the stochastic orders of two coherent systems with i.i.d. components but having different structures are given by the following Theorem 4 .

Theorem 4. Let $T_{j}=\tau_{j}\left(X_{1}, X_{2}, \ldots, X_{n}\right)$ be the lifetime of two coherent systems, where $X_{1}, X_{2}, \ldots, X_{n}$ are i.i.d random variables with common distribution function $F$. Suppose that coherent system $T_{j}$ has signature vector $\mathbf{s}^{(j)}=\left(s_{1}^{(j)}, \ldots, s_{i}^{(j)}, 0, \ldots, 0\right)$ and conditional signature vector $\mathbf{q}^{(j)}\left(t_{1}, t_{2}\right)=$ $\left(0, \ldots, 0, q_{r+1}^{(j)}\left(r, t_{1}, t_{2}\right), \ldots, q_{i}^{(j)}\left(r, t_{1}, t_{2}\right), 0, \ldots, 0\right), j=1,2$. Subsequently, for any $0<t_{1}<t_{2}$, we have

(i) If $\mathbf{q}^{(1)}\left(t_{1}, t_{2}\right) \leq s t \mathbf{q}^{(2)}\left(t_{1}, t_{2}\right)$, then

$$
\left(X_{k: n}-t_{2} \mid \operatorname{Ar}\left(t_{1}\right), T_{1}=t_{2}\right) \geq_{s t}\left(X_{k: n}-t_{2} \mid \operatorname{Ar}\left(t_{1}\right), T_{2}=t_{2}\right) ;
$$

(ii) If $\mathbf{q}^{(1)}\left(t_{1}, t_{2}\right) \leq_{r h} \mathbf{q}^{(2)}\left(t_{1}, t_{2}\right)$, then

$$
\left(X_{k: n}-t_{2} \mid A r\left(t_{1}\right), T_{1}=t_{2}\right) \geq_{h r}\left(X_{k: n}-t_{2} \mid A r\left(t_{1}\right), T_{2}=t_{2}\right) ;
$$


(iii) If $\mathbf{q}^{(1)}\left(t_{1}, t_{2}\right) \leq_{h r} \mathbf{q}^{(2)}\left(t_{1}, t_{2}\right)$, then

$$
\left(X_{k: n}-t_{2} \mid A r\left(t_{1}\right), T_{1}=t_{2}\right) \geq_{r h}\left(X_{k: n}-t_{2} \mid A r\left(t_{1}\right), T_{2}=t_{2}\right)
$$

(iv) If $\mathbf{q}^{(1)}\left(t_{1}, t_{2}\right) \leq_{l r} \mathbf{q}^{(2)}\left(t_{1}, t_{2}\right)$, then

$$
\left(X_{k: n}-t_{2} \mid \operatorname{Ar}\left(t_{1}\right), T_{1}=t_{2}\right) \geq_{l r}\left(X_{k: n}-t_{2} \mid A r\left(t_{1}\right), T_{2}=t_{2}\right) \text {. }
$$

Proof. (i) According to Theorem 1 and Lemma 2, the reliability function of $\left(X_{k: n}-t_{2} \mid A r\left(t_{1}\right), T_{j}=t_{2}\right)$, $j=1,2$, can be represented as

$$
\mathbb{P}\left(X_{k: n}-t_{2} \mid A r\left(t_{1}\right), T_{j}=t_{2}\right)=\sum_{m=r+1}^{i} q_{m}^{(j)}\left(r, t_{1}, t_{2}\right) \mathbb{P}\left(X_{k: n}-t_{2} \mid A r\left(t_{1}\right), X_{m: n}=t_{2}\right)
$$

Because $\mathbf{q}^{(1)}\left(t_{1}, t_{2}\right) \leq s t \mathbf{q}^{(2)}\left(t_{1}, t_{2}\right)$, thus, from Theorem 2 and Lemma 1(ii), it implies that

$$
\sum_{m=r+1}^{i} q_{m}^{(1)}\left(r, t_{1}, t_{2}\right) \mathbb{P}\left(Z_{k-m: n-m}^{t_{2}}>x\right) \geq \sum_{m=r+1}^{i} q_{m}^{(2)}\left(r, t_{1}, t_{2}\right) \mathbb{P}\left(Z_{k-m: n-m}^{t_{2}}>x\right) .
$$

Hence, from (9) and (10), we have

$$
\mathbb{P}\left(X_{k: n}-t_{2}>x \mid \operatorname{Ar}\left(t_{1}\right), T_{1}=t_{2}\right) \geq \mathbb{P}\left(X_{k: n}-t_{2}>x \mid A r\left(t_{1}\right), T_{2}=t_{2}\right)
$$

The proof of part(i) is completed.

(ii) In order to obtain the required result, it is suffices to show that

$$
\frac{\mathbb{P}\left(X_{k: n}-t_{2}>x \mid A r\left(t_{1}\right), T_{1}=t_{2}\right)}{\mathbb{P}\left(X_{k: n}-t_{2}>x \mid A r\left(t_{1}\right), T_{2}=t_{2}\right)}
$$

is increasing in $x \in \mathbb{R}^{+}$, that is, for any $0<x_{1}<x_{2}$,

$$
\frac{\mathbb{P}\left(X_{k: n}-t_{2}>x_{2} \mid A r\left(t_{1}\right), T_{1}=t_{2}\right)}{\mathbb{P}\left(X_{k: n}-t_{2}>x_{2} \mid A r\left(t_{1}\right), T_{2}=t_{2}\right)} \geq \frac{\mathbb{P}\left(X_{k: n}-t_{2}>x_{1} \mid A r\left(t_{1}\right), T_{1}=t_{2}\right)}{\mathbb{P}\left(X_{k: n}-t_{2}>x_{1} \mid A r\left(t_{1}\right), T_{2}=t_{2}\right)},
$$

which is equivalent to

$$
\begin{aligned}
& \frac{\sum_{m=r+1}^{i} q_{m}^{(1)}\left(r, t_{1}, t_{2}\right) \mathbb{P}\left(X_{k: n}-t_{2}>x_{2} \mid A r\left(t_{1}\right), X_{m: n}=t_{2}\right)}{\sum_{m=r+1}^{i} q_{m}^{(1)}\left(r, t_{1}, t_{2}\right) \mathbb{P}\left(X_{k: n}-t_{2}>x_{1} \mid A r\left(t_{1}\right), X_{m: n}=t_{2}\right)} \\
& \geq \frac{\sum_{m=r+1}^{i} q_{m}^{(2)}\left(r, t_{1}, t_{2}\right) \mathbb{P}\left(X_{k: n}-t_{2}>x_{2} \mid A r\left(t_{1}\right), X_{m: n}=t_{2}\right)}{\sum_{m=r+1}^{i} q_{m}^{(2)}\left(r, t_{1}, t_{2}\right) \mathbb{P}\left(X_{k: n}-t_{2}>x_{1} \mid A r\left(t_{1}\right), X_{m: n}=t_{2}\right)} .
\end{aligned}
$$

Define, for $0<x_{1}<x_{2}, m=r+1, \ldots, i$,

$\alpha(m)=\mathbb{P}\left(X_{k: n}-t_{2}>x_{2} \mid A r\left(t_{1}\right), X_{m: n}=t_{2}\right), \quad \beta(m)=\mathbb{P}\left(X_{k: n}-t_{2}>x_{1} \mid A r\left(t_{1}\right), X_{m: n}=t_{2}\right)$.

According to Theorem 2,

$$
\frac{\mathbb{P}\left(X_{k: n}-t_{2}>x \mid A r\left(t_{1}\right), X_{m+1: n}=t_{2}\right)}{\mathbb{P}\left(X_{k: n}-t_{2}>x \mid A r\left(t_{1}\right), X_{m: n}=t_{2}\right)}
$$

is decreasing in $x \in \mathbb{R}^{+}$. That is, for any $x_{1} \leq x_{2}$, we have

$$
\frac{\mathbb{P}\left(X_{k: n}-t_{2}>x_{2} \mid A r\left(t_{1}\right), X_{m+1: n}=t_{2}\right)}{\mathbb{P}\left(X_{k: n}-t_{2}>x_{1} \mid A r\left(t_{1}\right), X_{m+1: n}=t_{2}\right)} \leq \frac{\mathbb{P}\left(X_{k: n}-t_{2}>x_{2} \mid A r\left(t_{1}\right), X_{m: n}=t_{2}\right)}{\mathbb{P}\left(X_{k: n}-t_{2}>x_{1} \mid A r\left(t_{1}\right), X_{m: n}=t_{2}\right)},
$$


thus, $\alpha(m) / \beta(m)$ is decreasing in $m$, note that $\beta(m)$ is also decreasing in $m$. Because $\mathbf{q}^{(1)}\left(t_{1}, t_{2}\right) \leq_{r h}$ $\mathbf{q}^{(2)}\left(t_{1}, t_{2}\right)$, hence, from Lemma 1(iii), (11) is increasing in $x \in \mathbb{R}^{+}$. This completes the proof of part(ii).

(iii) By Lemma 1 (iv), the proof of part (iii) is similar to that of part (ii), and is, thus, is omitted here.

(iv) For any $0 \leq t_{1}<t_{2}$, let $f_{T_{j}}\left(t_{1}, t_{2}, x\right)$ denote the density function of $\left(X_{k: n}-t_{2} \mid A r\left(t_{1}\right), T_{j}=t_{2}\right)$, $j=1,2$. In order to obtain the required conclusion, we need to prove that

$$
\frac{f_{T_{1}}\left(t_{1}, t_{2}, x\right)}{f_{T_{2}}\left(t_{1}, t_{2}, x\right)}
$$

is increasing in $x \in \mathbb{R}^{+}$,; hence, for any $x_{1} \leq x_{2}$,

$$
\frac{\sum_{m=r+1}^{i} q_{m}^{(1)}\left(r, t_{1}, t_{2}\right) h_{m}\left(t_{1}, t_{2}, x_{1}\right)}{\sum_{m=r+1}^{i} q_{m}^{(2)}\left(r, t_{1}, t_{2}\right) h_{m}\left(t_{1}, t_{2}, x_{1}\right)} \leq \frac{\sum_{m=r+1}^{i} q_{m}^{(1)}\left(r, t_{1}, t_{2}\right) h_{m}\left(t_{1}, t_{2}, x_{2}\right)}{\sum_{m=r+1}^{n} q_{m}^{(2)}\left(r, t_{1}, t_{2}\right) h_{m}\left(t_{1}, t_{2}, x_{2}\right)}
$$

which is equivalent to

$$
\begin{aligned}
& \sum_{m=r+1}^{i} \sum_{l=r+1}^{i} q_{m}^{(1)}\left(r, t_{1}, t_{2}\right) q_{l}^{(2)}\left(r, t_{1}, t_{2}\right)\left[h_{m}\left(t_{1}, t_{2}, x_{2}\right) h_{l}\left(t_{1}, t_{2}, x_{1}\right)-h_{m}\left(t_{1}, t_{2}, x_{1}\right) h_{l}\left(t_{1}, t_{2}, x_{2}\right)\right] \\
= & \sum_{m=r+1}^{i} \sum_{l=r+1}^{m} q_{m}^{(1)}\left(r, t_{1}, t_{2}\right) q_{l}^{(2)}\left(r, t_{1}, t_{2}\right)\left[h_{m}\left(t_{1}, t_{2}, x_{2}\right) h_{l}\left(t_{1}, t_{2}, x_{1}\right)-h_{m}\left(t_{1}, t_{2}, x_{1}\right) h_{l}\left(t_{1}, t_{2}, x_{2}\right)\right] \\
& +\sum_{m=r+1}^{i} \sum_{l=m}^{i} q_{m}^{(1)}\left(r, t_{1}, t_{2}\right) q_{l}^{(2)}\left(r, t_{1}, t_{2}\right)\left[h_{m}\left(t_{1}, t_{2}, x_{2}\right) h_{l}\left(t_{1}, t_{2}, x_{1}\right)-h_{m}\left(t_{1}, t_{2}, x_{1}\right) h_{l}\left(t_{1}, t_{2}, x_{2}\right)\right]
\end{aligned}
$$

is nonnegative, where $h_{m}\left(t_{1}, t_{2}, x\right)$ is the density function of $\left(X_{k: n}-t_{2} \mid \operatorname{Ar}\left(t_{1}\right), X_{m: n}=t_{2}\right)$. Note that the second term in the right side of (12) can be represented as

$$
\begin{aligned}
& \sum_{m=r+1}^{i} \sum_{l=m}^{i} q_{m}^{(1)}\left(r, t_{1}, t_{2}\right) q_{l}^{(2)}\left(r, t_{1}, t_{2}\right)\left[h_{m}\left(t_{1}, t_{2}, x_{2}\right) h_{l}\left(t_{1}, t_{2}, x_{1}\right)-h_{m}\left(t_{1}, t_{2}, x_{1}\right) h_{l}\left(t_{1}, t_{2}, x_{2}\right)\right] \\
= & \sum_{l=r+1}^{i} \sum_{m=r+1}^{l} q_{m}^{(1)}\left(r, t_{1}, t_{2}\right) q_{l}^{(2)}\left(r, t_{1}, t_{2}\right)\left[h_{m}\left(t_{1}, t_{2}, x_{2}\right) h_{l}\left(t_{1}, t_{2}, x_{1}\right)-h_{m}\left(t_{1}, t_{2}, x_{1}\right) h_{l}\left(t_{1}, t_{2}, x_{2}\right)\right] \\
= & \sum_{m=r+1}^{i} \sum_{l=r+1}^{m} q_{l}^{(1)}\left(r, t_{1}, t_{2}\right) q_{m}^{(2)}\left(r, t_{1}, t_{2}\right)\left[h_{l}\left(t_{1}, t_{2}, x_{2}\right) h_{m}\left(t_{1}, t_{2}, x_{1}\right)-h_{l}\left(t_{1}, t_{2}, x_{1}\right) h_{m}\left(t_{1}, t_{2}, x_{2}\right)\right] .
\end{aligned}
$$

Thus, the right side of (12) can be rewritten by

$$
\begin{aligned}
& \sum_{m=r+1}^{i} \sum_{l=r+1}^{m} {\left[q_{m}^{(1)}\left(r, t_{1}, t_{2}\right) q_{l}^{(2)}\left(r, t_{1}, t_{2}\right)-q_{m}^{(2)}\left(r, t_{1}, t_{2}\right) q_{l}^{(1)}\left(r, t_{1}, t_{2}\right)\right] } \\
& \times\left[h_{m}\left(t_{1}, t_{2}, x_{2}\right) h_{l}\left(t_{1}, t_{2}, x_{1}\right)-h_{m}\left(t_{1}, t_{2}, x_{1}\right) h_{l}\left(t_{1}, t_{2}, x_{2}\right)\right] .
\end{aligned}
$$

Due to $\mathbf{q}^{(1)}\left(t_{1}, t_{2}\right) \leq_{l r} \mathbf{q}^{(2)}\left(t_{1}, t_{2}\right)$ implying that $\left(q_{m}^{(2)}\left(r, t_{1}, t_{2}\right)\right) /\left(q_{m}^{(1)}\left(r, t_{1}, t_{2}\right)\right)$ is increasing in $m(m=r+1, \ldots, i)$, which is,

$$
q_{m}^{(1)}\left(r, t_{1}, t_{2}\right) q_{l}^{(2)}\left(r, t_{1}, t_{2}\right)-q_{m}^{(2)}\left(r, t_{1}, t_{2}\right) q_{l}^{(1)}\left(r, t_{1}, t_{2}\right) \leq 0, \text { for } l<m .
$$

Additionally, according to Theorem 2, for $l<m$, we have

$$
h_{m}\left(t_{1}, t_{2}, x_{2}\right) h_{l}\left(t_{1}, t_{2}, x_{1}\right)-h_{m}\left(t_{1}, t_{2}, x_{1}\right) h_{l}\left(t_{1}, t_{2}, x_{2}\right) \leq 0, \text { for } x_{1} \leq x_{2}
$$

Hence, it is follows from (14) and (15) that (13) is nonnegative. The proof is completed. 
Remark 3. It is noted that Theorem 4 extends Theorem 2.4 of [19] to the stochastic orders of residual lifetimes of the unfailed components under double monitoring.

The following example illustrates the results of Theorem 4 .

Example 3. Assume that $X_{1}, X_{2}, X_{3}$, and $X_{4}$ are i.i.d. random variables. Consider two coherent systems with lifetime $T_{1}=\max \left(\min \left(X_{1}, X_{2}, X_{3}\right), \min \left(X_{2}, X_{3}, X_{4}\right)\right)$ and $T_{2}=\min \left(X_{1}, \max \left(X_{2}, X_{3}, X_{4}\right)\right)$, which have the signature vectors $\mathbf{s}^{(\mathbf{1})}=\left(\frac{1}{2}, \frac{1}{2}, 0,0\right)$ and $\mathbf{s}^{(2)}=\left(\frac{1}{4}, \frac{1}{4}, \frac{1}{2}, 0\right)$, respectively. Suppose that there is one component failed at time $t_{1}$, and the system failed at time $t_{2}\left(>t_{1}\right)$. Set $X$ has a Weibull distribution, i.e., $\bar{F}(\lambda, \alpha ; x)=e^{-\lambda^{\alpha} x^{\alpha}}, \lambda=0.4, \alpha=1.2$ and $r=1, k=4$.

(i) Figure 5 plots the reliability functions of $R X_{4: 4}^{T_{1}}$ and $R X_{4: 4}^{T_{2}}$, it is easily see that $\bar{F}\left(R X_{4: 4}^{T_{1}} ; x\right) \geq \bar{F}\left(R X_{4: 4}^{T_{2}} ; x\right)$;

(ii) As in Figure 6, it is clearly seen that $\left(\bar{F}\left(R X_{4: 4}^{T_{1}} ; x\right)\right) /\left(\bar{F}\left(R X_{4: 4}^{T_{2}} ; x\right)\right)$ is increasing in $x \in \mathbb{R}^{+}$;

(iii) Figure 7 clearly shows that $\left(F\left(R X_{4: 4}^{T_{1}} ; x\right)\right) /\left(F\left(R X_{4: 4}^{T_{2}} ; x\right)\right)$ is increasing in $x \in \mathbb{R}^{+}$;

(iv) From Figure 8 , we clearly see that $\left(f\left(R X_{4: 4}^{T_{1}} ; x\right)\right) /\left(f\left(R X_{4: 4}^{T_{1}} ; x\right)\right)$ is increasing in $x \in \mathbb{R}^{+}$. Hence, it follows from (i), (ii), (iii), and (iv) that confirms the validity of Theorem 4.
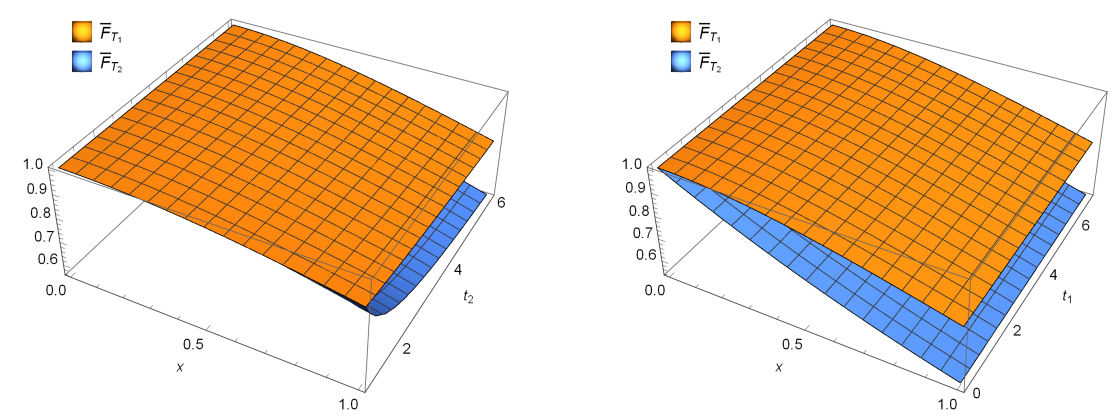

Figure 5. The graphs of the reliability function of $R X_{4: 4}^{T_{1}}\left(t_{1}, t_{2}\right)$ and $R X_{4: 4}^{T_{2}}\left(t_{1}, t_{2}\right)$, for the $t_{1}=1$ (left) and $t_{2}=8$ (right).
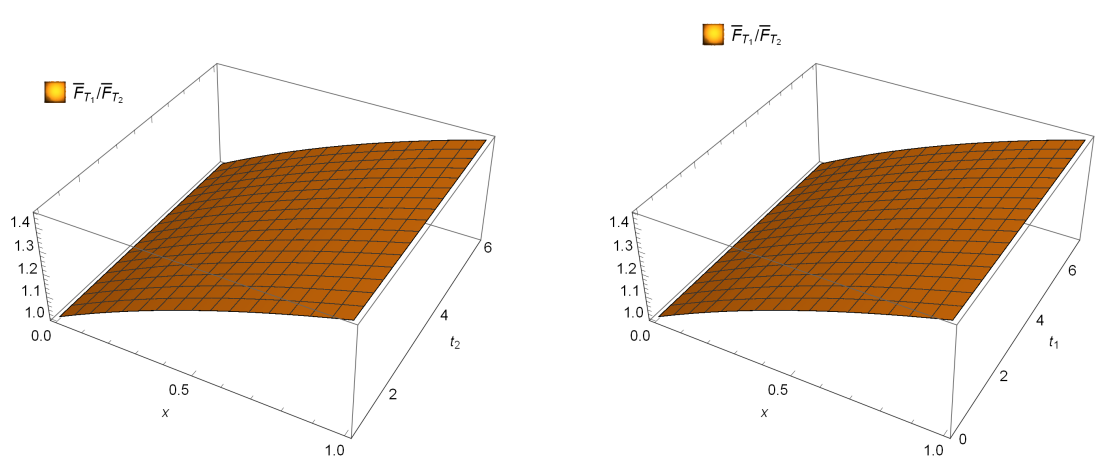

Figure 6. The graphs of the $\left(\bar{F}\left(R X_{4: 4}^{T_{1}} ; x\right)\right) /\left(\bar{F}\left(R X_{4: 4}^{T_{2}} ; x\right)\right)$, for the $t_{1}=1$ (left) and $t_{2}=8$ (right). 

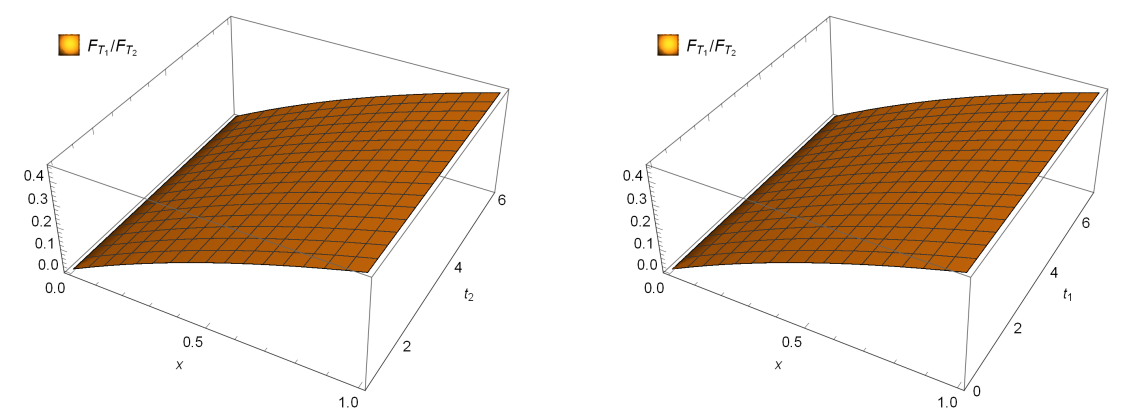

Figure 7. The graphs of the $\left(F\left(R X_{4: 4}^{T_{1}} ; x\right)\right) /\left(F\left(R X_{4: 4}^{T_{2}} ; x\right)\right)$, for the $t_{1}=1$ (left) and $t_{2}=8$ (right).
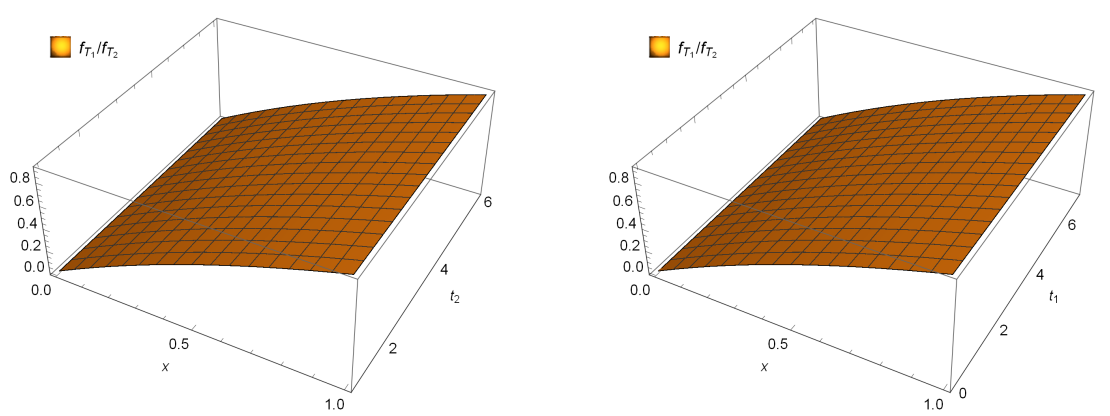

Figure 8. The graphs of the $\left(f\left(R X_{4: 4}^{T_{1}} ; x\right)\right) /\left(f\left(R X_{4: 4}^{T_{1}} ; x\right)\right)$, for the $t_{1}=1$ (left) and $t_{2}=8$ (right).

In the next, we will consider aging property of the residual lifetimes on survival components in a coherent system. Before giving the theorem, we first introduce a lemma.

Lemma 3. Assume that $X_{1}, X_{2}, \ldots, X_{n}$ are i.i.d. random variables that have common distribution function $F$. If $X_{i}$ is IFR(increasing failure rate), then for $0 \leq r<k, \mathbb{P}\left(X_{k: n}-t_{2}>x \mid A r\left(t_{1}\right), X_{m: n}=t_{2}\right)$ is decreasing in $t_{2}\left(>t_{1}\right)$.

Proof. For any $x \in \mathbb{R}^{+}$, and $0<t_{1}<t_{2,}$, note that

$$
\begin{aligned}
& \mathbb{P}\left(t_{2}-X_{k: n}>x \mid X_{r: n}=t_{1}, X_{m: n}=t_{2}\right) \\
= & \sum_{j=n-k+1}^{n-m}\left(\begin{array}{c}
n-m \\
j
\end{array}\right)\left(\bar{G}_{t_{2}}(x)\right)^{j}\left(1-\bar{G}_{t_{2}}(x)\right)^{n-m-j} \\
= & \int_{1-\bar{G}_{t_{2}}(x)}^{1}(k-m)\left(\begin{array}{l}
n-m \\
k-m
\end{array}\right) u^{k-m-1}(1-u)^{n-k+m} \mathrm{~d} u,
\end{aligned}
$$

where $\bar{G}_{t_{2}}(x)=\frac{\bar{F}\left(t_{2}+x\right)}{\bar{F}\left(t_{2}\right)}$. Note that $X_{i}$ is IFR, which is equivalent to $\bar{G}_{t_{2}}(x)=\frac{\bar{F}\left(t_{2}+x\right)}{\bar{F}\left(t_{2}\right)}$ is decreasing in $t_{2}$. Thus, it follows from (16) that $P\left(X_{k: n}-t_{2}>x \mid A r\left(t_{1}\right), X_{m: n}=t_{2}\right)$ is decreasing in $t_{2}$.

Theorem 5. Consider that a coherent system is composed of $n$ i.i.d. components with lifetimes $X_{1}, X_{2}, \ldots, X_{n}$. Suppose that the system has signature vector $\mathbf{s}=\left(s_{1}, s_{2}, \ldots, s_{i}, 0, \ldots, 0\right)$. If $X_{i}$ is $\operatorname{IFR}$, then $\mathbb{P}\left(R X_{k: n}\left(t_{1}, t_{2}\right)>\right.$ $x)$ is decreasing in $t_{2}\left(>t_{1}\right)$. 
Proof. First, taking the partial derivative of reliability function of $R X_{k: n}\left(t_{1}, t_{2}\right)$ with respect to $t_{2}$ gives rise to

$$
\begin{aligned}
& \frac{\partial \mathbb{P}\left(X_{k: n}-t_{2}>x \mid A r\left(t_{1}\right), T=t_{2}\right)}{\partial t_{2}} \\
= & \frac{\partial \sum_{m=r+1}^{i} q_{m}\left(r, t_{1}, t_{2}\right) p\left(X_{k: n}-t_{2}>x \mid A r\left(t_{1}\right), T=t_{2}\right)}{\partial t_{2}} \\
= & \sum_{m=r+1}^{i} \frac{\partial q_{m}\left(r, t_{1}, t_{2}\right)}{\partial t_{2}} \mathbb{P}\left(X_{k: n}-t_{2}>x \mid A r\left(t_{1}\right), T=t_{2}\right) \\
& +\sum_{m=r+1}^{i} q_{m}\left(r, t_{1}, t_{2}\right) \frac{\partial \mathbb{P}\left(X_{k: n}-t_{2}>x \mid A r\left(t_{1}\right), X_{m: n}=t_{2}\right)}{\partial t_{2}} .
\end{aligned}
$$

Because $F$ is IFR, it follows from Lemma 3 that the second term in (17) is nonpositive. Note that

$$
\begin{aligned}
\frac{\partial q_{m}\left(r, t_{1}, t_{2}\right)}{\partial t_{2}} & =\frac{\partial\left(\frac{s_{m} C_{r, m}^{n}\left(\phi\left(t_{1}, t_{2}\right)\right)^{m}}{\sum_{j=r+1}^{i} s_{j} C_{r, j}^{n}\left(\phi\left(t_{1}, t_{2}\right)\right)^{j}}\right)}{\partial t_{2}} \\
& =\frac{\frac{\partial \phi\left(t_{1}, t_{2}\right)}{\partial t_{2}} \sum_{j=r+1}^{i} s_{m} s_{j} C_{r, m}^{n} C_{r, j}^{n}\left(\phi\left(t_{1}, t_{2}\right)\right)^{m+j-1}(m-j)}{\left(\sum_{j=r+1}^{i} s_{j} C_{r, j}^{n}\left(\phi\left(t_{1}, t_{2}\right)\right)^{j}\right)^{2}} .
\end{aligned}
$$

Let $g(m)=\mathbb{P}\left(X_{k: n}-t_{2}>x \mid A r\left(t_{1}\right), X_{m: n}=t_{2}\right)$, then

$$
\begin{aligned}
& \sum_{m=r+1}^{i} \frac{\partial q_{m}\left(r, t_{1}, t_{2}\right)}{\partial t_{2}} g(m) \\
= & \sum_{m=r+1}^{i} \frac{\frac{\partial \phi\left(t_{1}, t_{2}\right)}{\partial t_{2}} \sum_{j=r+1}^{i} s_{m} s_{j} C_{r, m}^{n} C_{r, j}^{n}\left(\phi\left(t_{1}, t_{2}\right)\right)^{m+j-1}(m-j)}{\left(\sum_{j=r+1}^{i} s_{j} C_{r, j}^{n}\left(\phi\left(t_{1}, t_{2}\right)\right)^{j}\right)^{2}} g(m) \\
\underline{\underline{s g n}} & \sum_{m=r+1}^{i} \sum_{j=r+1}^{i} s_{m} s_{j} C_{r, m}^{n} C_{r, j}^{n}\left(\phi\left(t_{1}, t_{2}\right)\right)^{m+j-1}(m-j) g(m) \\
= & \sum_{m=r+1}^{i} \sum_{j=r+1}^{m} s_{m} s_{j} C_{r, m}^{n} C_{r, j}^{n}\left(\phi\left(t_{1}, t_{2}\right)\right)^{m+j-1}(m-j) g(m) \\
= & +\sum_{m=r+1}^{i} \sum_{j=m}^{i} s_{m} s_{j} C_{r, m}^{n} C_{r, j}^{n}\left(\phi\left(t_{1}, t_{2}\right)\right)^{m+j-1}(m-j) g(m) \\
& \sum_{m=r+1}^{i} \sum_{j=r+1}^{m} s_{m} s_{j} C_{r, m}^{n} C_{r, j}^{n}\left(\phi\left(t_{1}, t_{2}\right)\right)^{m+j-1}(m-j) g(m) \\
= & \sum_{j=r+1}^{i} \sum_{m=r+1}^{j} s_{m} s_{j} C_{r, m}^{n} C_{r, j}^{n}\left(\phi\left(t_{1}, t_{2}\right)\right)^{m+j-1}(m-j) g(m) \\
& \sum_{m=r+1}^{i} \sum_{j=r+1}^{m} s_{m} s_{j} C_{r, m}^{n} C_{r, j}^{n}\left(\phi\left(t_{1}, t_{2}\right)\right)^{m+j-1}(m-j) g(m) \\
& -\sum_{m=r+1}^{i} \sum_{j=r+1}^{m} s_{m} s_{j} C_{r, m}^{n} C_{r, j}^{n}\left(\phi\left(t_{1}, t_{2}\right)\right)^{m+j-1}(m-j) g(j) \\
= & \sum_{m=r+1}^{i} \sum_{j=r+1}^{m} s_{m} s_{j} C_{r, m}^{n} C_{r, j}^{n}\left(\phi\left(t_{1}, t_{2}\right)\right)^{m+j-1}[(m-j)(g(m)-g(j))] .
\end{aligned}
$$


Hence, according to Theorem 2, $g(m)$ is decreasing in $m$, which implies $(m-j)(g(m)-g(j)) \leq 0$, that is, (18) is nonpositive. Thus, (17) is nonpositive. The proof is completed.

Remark 4. It should be noted that Theorem 5 generalizes Theorem 2.6 in [19] to the case of coherent system under double monitoring.

Notice that random variable $X$ is IFR in Example 1 when $\alpha>1$. From the right of Figures 2 and 3 , we can clearly see that $\mathbb{P}\left(R X_{k: n}\left(t_{1}, t_{2}\right)>x\right)$ is decreasing in $t_{2}\left(>t_{1}\right)$, which confirms the validity of Theorem 5.

Theorem 6. Suppose that two coherent systems are composed of $n$ i.i.d. components with lifetimes $X_{1}, X_{2}, \ldots, X_{n}$ and $Y_{1}, Y_{2}, \ldots, Y_{n}$, which have distribution functions $F$ and $G$, respectively. Let $T_{1}=$ $\tau\left(X_{1}, X_{2}, \ldots, X_{n}\right)$ and $T_{2}=\tau\left(Y_{1}, Y_{2}, \ldots, Y_{n}\right)$ be the lifetime of two coherent systems that have common signature vector $\mathbf{s}=\left(s_{1}, \ldots, s_{i}, 0, \ldots, 0\right)$. If $X_{1} \leq_{h r} Y_{1}$, then

$$
\left(X_{k: n}-t_{2} \mid A r\left(t_{1}\right), T_{X}=t_{2}\right) \leq_{s t}\left(Y_{k: n}-t_{2} \mid Y_{r: n}=t_{1}, T_{Y}=t_{2}\right) .
$$

Proof. For $m=r+1, \ldots, i$, and $0<t_{1}<t_{2}$, let

$$
q_{m}^{X}\left(r, t_{1}, t_{2}\right)=\frac{s_{m} C_{r, m}^{n}\left(\phi^{X}\left(t_{1}, t_{2}\right)\right)^{m}}{\sum_{j=r+1}^{i} s_{j} C_{r, j}^{n}\left(\phi^{X}\left(t_{1}, t_{2}\right)\right)^{j}}, \quad q_{m}^{Y}\left(r, t_{1}, t_{2}\right)=\frac{s_{m} C_{r, m}^{n}\left(\phi^{Y}\left(t_{1}, t_{2}\right)\right)^{m}}{\sum_{j=i}^{n} s_{j} C_{r, j}^{n}\left(\phi^{Y}\left(t_{1}, t_{2}\right)\right)^{j}},
$$

where $\phi^{X}\left(t_{1}, t_{2}\right)=\frac{\bar{F}\left(t_{1}\right)}{\bar{F}\left(t_{2}\right)}-1$ and $\phi^{Y}\left(t_{1}, t_{2}\right)=\frac{\bar{G}\left(t_{1}\right)}{\bar{G}\left(t_{2}\right)}-1$. According to Theorem 1 and Lemma 2, the reliability function of inactivity times $R X_{k: n}\left(t_{1}, t_{2}\right)$ and $R Y_{k: n}\left(t_{1}, t_{2}\right)$ are

$$
\mathbb{P}\left(X_{k: n}-t_{2}>x \mid A r\left(t_{1}\right), T_{X}=t_{2}\right)=\sum_{m=r+1}^{i} \frac{s_{m} C_{r, m}^{n}\left(\phi^{X}\left(t_{1}, t_{2}\right)\right)^{m}}{\sum_{j=r+1}^{i} s_{j} C_{r, j}^{n}\left(\phi^{X}\left(t_{1}, t_{2}\right)\right)^{j}} \mathbb{P}\left(Z_{k-m: n-m}^{t_{2}, X}>x\right),
$$

and

$$
\mathbb{P}\left(Y_{k: n}-t_{2}>x \mid A r\left(t_{1}\right), T_{Y}=t_{2}\right)=\sum_{m=r+1}^{i} \frac{s_{m} C_{r, m}^{n}\left(\phi^{Y}\left(t_{1}, t_{2}\right)\right)^{m}}{\sum_{j=r+1}^{i} s_{j} C_{r, j}^{n}\left(\phi^{Y}\left(t_{1}, t_{2}\right)\right)^{j}} \mathbb{P}\left(Z_{k-m: n-m}^{t_{2}, Y}>x\right),
$$

respectively, where $Z_{k-m: n-m}^{t_{2}, X}$ is the $(k-m)$ th order statistics in $(n-m)$ i.i.d. random variables with distributed distribution $\left(F\left(t_{2}+x\right)-F\left(t_{2}\right)\right) /\left(1-F\left(t_{2}\right)\right)$, and $Z_{k-m: n-m}^{t_{2}, Y}$ is the $(k-m)$ th order statistics in $(n-m)$ i.i.d. random variables with distributed distribution $\left(G\left(t_{2}+x\right)-G\left(t_{2}\right)\right) /\left(1-G\left(t_{2}\right)\right)$.

Thus, in order to show the desired conclusion, we only need to prove that

$$
\sum_{m=r+1}^{i} q_{m}^{Y}\left(r, t_{1}, t_{2}\right) \mathbb{P}\left(Z_{k-m: n-m}^{t_{2}, Y}>x\right) \geq \sum_{m=r+1}^{i} q_{m}^{X}\left(r, t_{1}, t_{2}\right) \mathbb{P}\left(Z_{k-m: n-m}^{t_{2}, X}>x\right),
$$

it is equivalent to

$$
\begin{aligned}
& \sum_{m=r+1}^{i} \sum_{j=r+1}^{i} s_{m} s_{j} C_{r, m}^{n} C_{r, j}^{n}\left(\phi^{Y}\left(t_{1}, t_{2}\right)\right)^{m}\left(\phi^{X}\left(t_{1}, t_{2}\right)\right)^{j} \mathbb{P}\left(Z_{k-m: n-m}^{t_{2}, Y}>x\right) \\
& -\sum_{m=r+1}^{i} \sum_{j=r+1}^{i} s_{m} s_{j} C_{r, m}^{n} C_{r, j}^{n}\left(\phi^{X}\left(t_{1}, t_{2}\right)\right)^{m}\left(\phi^{Y}\left(t_{1}, t_{2}\right)\right)^{j} \mathbb{P}\left(Z_{k-m: n-m}^{t_{2}, X}>x\right) \geq 0,
\end{aligned}
$$


that is,

$$
\begin{gathered}
\sum_{m=r+1}^{i} \sum_{j=r+1}^{i} s_{m} s_{j} C_{r, m}^{n} C_{r, j}^{n}\left(\phi^{Y}\left(t_{1}, t_{2}\right)\right)^{m}\left(\phi^{X}\left(t_{1}, t_{2}\right)\right)^{j}\left[\mathbb{P}\left(Z_{k-m: n-m}^{t_{2}, Y}>x\right)-\mathbb{P}\left(Z_{k-m: n-m}^{t_{2}, X}>x\right)\right] \\
+\sum_{m=r+1}^{i} \sum_{j=r+1}^{i} s_{m} s_{j} C_{r, m}^{n} C_{r, j}^{n} \mathbb{P}\left(Z_{k-m: n-m}^{t_{2}, X}>x\right)\left[\left(\phi^{Y}\left(t_{1}, t_{2}\right)\right)^{m}\left(\phi^{X}\left(t_{1}, t_{2}\right)\right)^{j}\right. \\
\left.-\left(\phi^{X}\left(t_{1}, t_{2}\right)\right)^{m}\left(\phi^{Y}\left(t_{1}, t_{2}\right)\right)^{j}\right] \geq 0 .
\end{gathered}
$$

Owing to $X_{1} \leq_{h r} Y_{1}$ meaning that $\bar{F}\left(t_{2}+x\right) / \bar{F}\left(t_{2}\right) \leq \bar{G}\left(t_{2}+x\right) / \bar{G}\left(t_{2}\right)$, it follows from (16) that

$$
\mathbb{P}\left(Z_{k-m: n-m}^{t_{2}, Y}>x\right)-\mathbb{P}\left(Z_{k-m: n-m}^{t_{2}, X}>x\right) \geq 0,
$$

which implies that the first term in the left side of (19) is positive. It is easily observed that the second term in the left side of (19) can be written as

$$
\begin{aligned}
& \sum_{m=r+1}^{i} \sum_{j=r+1}^{i} s_{m} s_{j} C_{r, m}^{n} C_{r, j}^{n} \mathbb{P}\left(Z_{k-m: n-m}^{t_{2}, X}>x\right)\left[\left(\phi^{Y}\left(t_{1}, t_{2}\right)\right)^{m}\left(\phi^{X}\left(t_{1}, t_{2}\right)\right)^{j}-\left(\phi^{X}\left(t_{1}, t_{2}\right)\right)^{m}\left(\phi^{Y}\left(t_{1}, t_{2}\right)\right)^{j}\right] \\
= & \sum_{m=r+1}^{i} \sum_{j=m}^{i} s_{m} s_{j} C_{r, m}^{n} C_{r, j}^{n} \mathbb{P}\left(Z_{k-m: n-m}^{t_{2}, X}>x\right)\left[\left(\phi^{Y}\left(t_{1}, t_{2}\right)\right)^{m}\left(\phi^{X}\left(t_{1}, t_{2}\right)\right)^{j}-\left(\phi^{X}\left(t_{1}, t_{2}\right)\right)^{m}\left(\phi^{Y}\left(t_{1}, t_{2}\right)\right)^{j}\right] \\
& +\sum_{m=r+1}^{i} \sum_{j=r+1}^{m-1} s_{m} s_{j} C_{r, m}^{n} C_{r, j}^{n} \mathbb{P}\left(Z_{k-m: n-m}^{t_{2}, X}>x\right)\left[\left(\phi^{Y}\left(t_{1}, t_{2}\right)\right)^{m}\left(\phi^{X}\left(t_{1}, t_{2}\right)\right)^{j}-\left(\phi^{X}\left(t_{1}, t_{2}\right)\right)^{m}\left(\phi^{Y}\left(t_{1}, t_{2}\right)\right)^{j}\right] \\
= & \sum_{m=r+1}^{i} \sum_{j=m}^{i} s_{m} s_{j} C_{r, m}^{n} C_{r, j}^{n} \mathbb{P}\left(Z_{k-m: n-m}^{t_{2}, X}>x\right)\left[\left(\phi^{Y}\left(t_{1}, t_{2}\right)\right)^{m}\left(\phi^{X}\left(t_{1}, t_{2}\right)\right)^{j}-\left(\phi^{X}\left(t_{1}, t_{2}\right)\right)^{m}\left(\phi^{Y}\left(t_{1}, t_{2}\right)\right)^{j}\right] \\
& +\sum_{j=r+1}^{i} \sum_{m=j}^{i} s_{m} s_{j} C_{r, m}^{n} C_{r, j}^{n} \mathbb{P}\left(Z_{k-m: n-m}^{t_{2}, X}>x\right)\left[\left(\phi^{Y}\left(t_{1}, t_{2}\right)\right)^{m}\left(\phi^{X}\left(t_{1}, t_{2}\right)\right)^{j}-\left(\phi^{X}\left(t_{1}, t_{2}\right)\right)^{m}\left(\phi^{Y}\left(t_{1}, t_{2}\right)\right)^{j}\right] \\
= & \sum_{m=r+1}^{i} \sum_{j=m}^{i} s_{m} s_{j} C_{r, m}^{n} C_{r, j}^{n} \mathbb{P}\left(Z_{k-m: n-m}^{t_{2}, X}>x\right)\left[\left(\phi^{Y}\left(t_{1}, t_{2}\right)\right)^{m}\left(\phi^{X}\left(t_{1}, t_{2}\right)\right)^{j}-\left(\phi^{X}\left(t_{1}, t_{2}\right)\right)^{m}\left(\phi^{Y}\left(t_{1}, t_{2}\right)\right)^{j}\right] \\
& -\sum_{m=r+1}^{i} \sum_{j=m}^{i} s_{m} s_{j} C_{r, m}^{n} C_{r, j}^{n} \mathbb{P}\left(Z_{k-j: n-j}^{t_{2}, X}>x\right)\left[\left(\phi^{Y}\left(t_{1}, t_{2}\right)\right)^{m}\left(\phi^{X}\left(t_{1}, t_{2}\right)\right)^{j}-\left(\phi^{X}\left(t_{1}, t_{2}\right)\right)^{m}\left(\phi^{Y}\left(t_{1}, t_{2}\right)\right)^{j}\right] \\
= & \sum_{m=r+1}^{i} \sum_{j=m}^{i} s_{m} s_{j} C_{r, m}^{n} C_{r, j}^{n}\left[\left(\phi^{Y}\left(t_{1}, t_{2}\right)\right)^{m}\left(\phi^{X}\left(t_{1}, t_{2}\right)\right)^{j}-\left(\phi^{X}\left(t_{1}, t_{2}\right)\right)^{m}\left(\phi^{Y}\left(t_{1}, t_{2}\right)\right)^{j}\right] \\
& \left.\times\left[\mathbb{P}\left(Z_{k-m: n-m}^{t_{2}, X}>x\right)-\mathbb{P}_{k}^{t_{2}, X}{ }_{k: n-j}>x\right)\right] .
\end{aligned}
$$

From Theorem 2, for any $m<j$, it holds that

$$
\mathbb{P}\left(Z_{k-m: n-m}^{t_{2}, X}>x\right)-\mathbb{P}\left(Z_{k-j: n-j}^{t_{2}, X}>x\right) \geq 0
$$

Because of $X_{1} \leq_{h r} Y_{1}$, it is easy to see that

$$
\left(\phi^{Y}\left(t_{1}, t_{2}\right)\right)^{m}\left(\phi^{X}\left(t_{1}, t_{2}\right)\right)^{j}-\left(\phi^{X}\left(t_{1}, t_{2}\right)\right)^{m}\left(\phi^{Y}\left(t_{1}, t_{2}\right)\right)^{j} \geq 0 .
$$

According to (21) and (22), the nonnegativity of (20) is verified, which yields the result.

Remark 5. Theorem 6 provides a sufficient condition for the usual stochastic order holds between two coherent systems having the same structure, but with two heterogeneous sets of i.i.d components. This extends Theorem 2.8 of [19] to the scenario of double monitoring.

The next example confirms the result of Theorem 6 . 
Example 4. Based on the Example 1 , suppose that $X_{1}$ and $Y_{1}$ have a Weibull distribution, i.e., $\bar{F}\left(\lambda_{1}, \alpha_{1} ; x\right)=$ $e^{-\lambda_{1}^{\alpha_{1}} x^{\alpha_{1}}}, \bar{G}\left(\lambda_{2}, \alpha_{2} ; x\right)=e^{-\lambda_{2}^{\alpha_{2}} x^{\alpha_{2}}}$. Let $\lambda_{1}=1.5, \lambda_{2}=0.4, \alpha_{1}=\alpha_{2}=0.6$. Owing to $\bar{G}\left(\lambda_{2}, \alpha_{2} ; x\right) / \bar{F}\left(\lambda_{1}, \alpha_{1} ; x\right)=e^{0.698345 x^{0.6}}$ is increasing in $x \in \mathbb{R}^{+}$, obviously, $X_{1} \leq_{h r} Y_{1}$.

(i) For $r=1, k=3$, Figure 9 plots the reliability functions of $R X_{3: 4}$ and $R Y_{3: 4}$, it is easily seen that $\bar{F}\left(R X_{3: 4} ; x\right) \leq \bar{G}\left(R Y_{3: 4} ; x\right)$;

(ii) For $r=1, k=4$, from which it is clear that the survival functions $\bar{F}\left(R X_{4: 4} ; x\right) \leq \bar{G}\left(R Y_{4: 4} ; x\right)$ in Figure 9.

Therefore, it follows from (i) and (ii), which confirms the validity of Theorem 6.
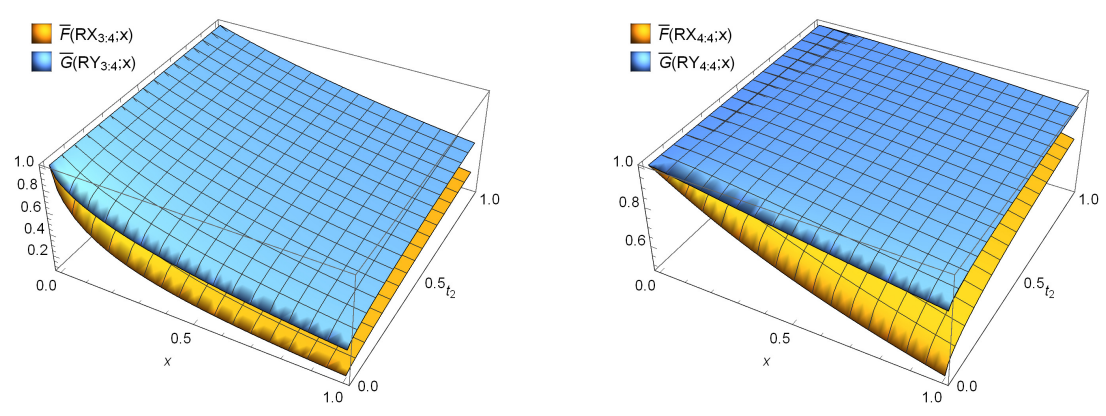

Figure 9. The reliability functions of $R X_{3: 4}$ and $R Y_{3: 4}$.

In combination with Theorem 4(i) and Theorem 6, it is easy to gain the next corollary.

Corollary 1. Suppose that $X_{1}, X_{2}, \ldots, X_{n}$ and $Y_{1}, Y_{2}, \ldots, Y_{n}$ are i.i.d. random variables with common distribution function $F$ and $G$, respectively. Let $T_{1}=\tau_{1}\left(X_{1}, X_{2}, \ldots, X_{n}\right), T_{2}=\tau_{2}\left(X_{1}, X_{2}, \ldots, X_{n}\right)$, and $T_{3}=\tau_{2}\left(Y_{1}, Y_{2}, \ldots, Y_{n}\right)$ be the lifetimes of three coherent systems, where $T_{1}$ has the signature vector $\mathbf{s}^{(1)}=$ $\left(s_{1}^{(1)}, \ldots, s_{i}^{(1)}, 0, \ldots, 0\right)$, and $T_{2}$ and $T_{3}$ have a common signature vector $\mathbf{s}^{(2,3)}=\left(s_{1}^{(2,3)}, \ldots, s_{i}^{(2,3)}, 0, \ldots, 0\right)$. If $\mathbf{p}^{(1)} \leq_{s t} \mathbf{p}^{(2)}$ and $X_{1} \geq_{h r} Y_{1}$, for any $t_{1}<t_{2}$, then

$$
\left(X_{k: n}-t_{2} \mid A r\left(t_{1}\right), T_{1}=t_{2}\right) \geq_{s t}\left(X_{k: n}-t_{2} \mid A r\left(t_{1}\right), T_{2}=t_{2}\right) \geq_{s t}\left(Y_{k: n}-t_{2} \mid A r\left(t_{1}\right), T_{3}=t_{2}\right) .
$$

\section{Conclusions}

In this manuscript, we consider the residual lifetime on unfailed components in a coherent system, which has $n$ i.i.d. components, under the assumption that there are $r(r<i)$ failed components at time $t_{1}$, but the system did not fail at time $t_{1}$, and the failure time of the system is time $t_{2}\left(>t_{1}\right)$. The survival function of the residual lifetimes on unfailed components in a coherent system can be expressed as a mixture representation of the survival function for the residual lifetime on the unfailed components with lifetime $X_{k: n}, k=i+1, \ldots, n$ in a $(n-m+1)$-out-of- $n$ system on the conditional that the failure time of the system is time $t_{2}\left(>t_{1}\right)$. With the help of the reliability function, some stochastic comparisons of condition residual lifetime of unfailed components between two coherent systems are obtained. We also provide the aging properties of the residual lifetime of unfailed components. In fact, we provide conditional random variable $\left(X_{k: n}-t_{2} \mid A r\left(t_{1}\right), T=t_{2}\right)$ that is a generalization of conditional random variable $\left(X_{k: n}-t \mid T=t\right)$, which is proposed in $([18,19])$.

In the practical case, the components of the system may be statistically dependent. In fact, it will be interesting to consider the residual lifetimes of unfailed components in a coherent system with dependent components. However, these problems remain open and merit further discussion, owing to the complexity of modeling for the system with dependent components.

Author Contributions: Methodology, Z.G. and R.Y.; software, Z.G. and J.Z.; validation, Z.G. and R.Y.; formal analysis, Z.G.; writing-original draft preparation, Z.G. and J.Z.; writing-review and editing, Z.G., J.Z. and R.Y., All authors have read and agreed to the published version of the manuscript. 
Funding: This research was supported by the National Natural Science Foundation of China $(11861058,71471148)$.

Acknowledgments: The authors are indebted to the insightful comments and suggestions from the Editors and three anonymous reviewers, which have greatly improved the presentation of the paper. Zhouxia Guo and Jiandong Zhang thank all the encouragement and help of Rongfang Yan during their graduate school years. Rongfang Yan acknowledges the financial support by the National Natural Science Foundation of China.

Conflicts of Interest: The authors declare no conflict of interest.

\section{References}

1. Barlow, E.; Proschan, F. Statistical Theory of Reliability and Life Testing: Probability Models (International Series in Decision Processes); Holt, Rinehart and Winston: New York, NY, USA, 1975.

2. Samaniego, F.J. On Closure of the IFR Class Under Formation of Coherent Systems. IEEE Trans. Reliab. 1985, R-34, 69-72. [CrossRef]

3. Kochar, S.; Mukerjee, H.; Samaniego, F.J. The signature of a coherent system and its application to comparisons among systems. Nav. Res. Logist. 1999, 46, 507-523. [CrossRef]

4. Navarro, J.; Rychlik, T. Reliability and expectation bounds for coherent systems with exchangeable components. J. Multivar. Anal. 2007, 98, 102-113. [CrossRef]

5. Marichal, J.; Mathonet, P. Extensions of system signatures to dependent lifetimes: Explicit expressions and interpretations. J. Multivar. Anal. 2011, 102, 931-936. [CrossRef]

6. Li, X.; Zhao, P. Some Aging Properties of the Residual Life of k-out-of-n Systems. IEEE Trans. Reliab. 2006, 55, 535-541. [CrossRef]

7. Khaledi, B.; Shaked, M. Ordering conditional lifetimes of coherent systems. J. Stat. Plan. Infer. 2007, 137, 1173-1184. [CrossRef]

8. Navarro, J.; Balakrishnan, N.; Samaniego, F.J. Mixture Representations of Residual Lifetimes of Used Systems. J. Appl. Probab. 2008, 45, 1097-1112. [CrossRef]

9. Li, X.; Zhao, P. Stochastic Comparison on General Inactivity Time and General Residual Life of k-Out-of-n Systems. Commun. Stat. Simul. Comput. 2008, 37, 1005-1019. [CrossRef]

10. Eryılmaz, S. On residual lifetime of coherent systems after the rth failure. Stat. Pap. 2011, 54, $243-250$. [CrossRef]

11. Balakrishnan, N.; Barmalzan, G.; Haidari, A. Stochastic Orderings and Ageing Properties of Residual Life Lengths of Live Components in (n-k+1)-Out-Of-n Systems. J. Appl. Probab. 2014, 51, 58-68. [CrossRef]

12. Navarro, J.; Gomis, M.C. Comparisons in the mean residual life order of coherent systems with identically distributed components. Appl. Stoch. Model. Bus. Ind. 2015, 32, 33-47. [CrossRef]

13. Salehi, E.; Tavangar, M. Stochastic comparisons on conditional residual lifetime and inactivity time of coherent systems with exchangeable components. Stat. Probab. Lett. 2019, 145, 327-337. [CrossRef]

14. Amini-Seresht, E.; Kelkinnama, M.; Zhang, Y. On the residual and past lifetimes of coherent systems under random monitoring. Probab. Eng. Inform. Sci. 2020, 1-16. [CrossRef]

15. Di Crescenzo, A.; Di Gironimo, P.; Kayal, S. Analysis of the Past Lifetime in a Replacement Model through Stochastic Comparisons and Differential Entropy. Mathematics 2020, 8, 1203. [CrossRef]

16. Balakrishnan, N.; Asadi, M. A proposed measure of residual life of live components of a coherent system. IEEE Trans. Reliab. 2011, 61, 41-49. [CrossRef]

17. Goliforushani, S.; Asadi, M. Stochastic ordering among inactivity times of coherent systems. Sankhya $B$ 2011, 73, 241-262. [CrossRef]

18. Goliforushani, S.; Asadi, M.; Balakrishnan, N. On the Residual and Inactivity Times of the Components of Used Coherent Systems. J. Appl. Probab. 2012, 49, 385-404. [CrossRef]

19. Nama, M.K.; Asadi, M. Stochastic Properties of Components in a Used Coherent System. Methodol. Comput. Appl. Probab. 2013, 16, 675-691. [CrossRef]

20. Tavangar, M. Conditional inactivity time of components in a coherent operating system. IEEE Trans. Reliab. 2015, 65, 359-369. [CrossRef]

21. Poursaeed, M.H.; Nematollahi, A.R. On the Mean Past and the Mean Residual Life Under Double Monitoring. Commun. Stat. Theory Methods 2008, 37, 1119-1133. [CrossRef]

22. Poursaeed, M.H.; Nematollahi, A.R. Some aspects of the mean past lifetime of a parallel system under double regularly checking. Statistics 2010, 44, 505-515. [CrossRef] 
23. Zhang, Z.; Yang, Y. Ordered properties on the residual life and inactivity time of -out-of- systems under double monitoring. Stat. Probab. Lett. 2010, 80, 711-717. [CrossRef]

24. Eryilmaz, S.; Bayramoglu, K. Residual Lifetime of Consecutive k-out-of- $n$ Systems Under Double Monitoring. IEEE Trans. Reliab. 2012, 61, 792-797. [CrossRef]

25. Zhang, Z.; Meeker, W.Q. Mixture Representations of Reliability in Coherent Systems and Preservation Results Under Double Monitoring. Commun. Stat. Theory Methods 2013, 42, 385-397. [CrossRef]

26. Parvardeh, A.; Balakrishnan, N.; Arshadipour, A. Conditional residual lifetimes of coherent systems under double monitoring. Commun. Stat. Theory Methods 2016, 46, 3401-3410. [CrossRef]

27. Parvardeh, A.; Balakrishnan, N.; Arshadipour, A. A note on the conditional residual lifetime of a coherent system under double monitoring. Commun. Stat. Theory Methods 2018, 47, 2373-2378. [CrossRef]

28. Shaked, M.; Shanthikumar, G. Stochastic Orders; Springer Science Business Media: Berlin/Heidelberg, Germany, 2007.

29. Belzunce, F.; Riquelme, C.M.; Mulero, J. An Introduction to Stochastic Orders; Academic Press: Cambridge, MA, USA, 2016.

30. Goli, S. On the conditional residual lifetime of coherent systems under double regularly checking. Nav. Res. Logist. 2019, 66, 352-363. [CrossRef]

31. Marshall, A.W.; Olkin, I. Life Distributions; Springer: Berlin/Heidelberg, Germany, 2007; Volume 13.

Publisher's Note: MDPI stays neutral with regard to jurisdictional claims in published maps and institutional affiliations.

(C) 2020 by the authors. Licensee MDPI, Basel, Switzerland. This article is an open access article distributed under the terms and conditions of the Creative Commons Attribution (CC BY) license (http://creativecommons.org/licenses/by/4.0/). 